\title{
CAIXA LÚDICA PARA IDOSOS: UMA NOVA PROPOSTA PSICODIAGNÓSTICA
}

\author{
LILIANA CREMASCHI LEONARDI
}

RESUMO

LEONARDI, L. C. Caixa Lúdica para Idosos: uma nova proposta psicodiagnóstica. 2011.138f. Dissertação de Mestrado, Instituto de Psicologia, Universidade de São Paulo, São Paulo, 2011.

O envelhecimento implica em alterações bio-psico-sociais, que refletem um processo individual, podendo ser vivido e resolvido diferentemente de acordo com a possibilidade de articulação entre as capacidades do indivíduo e os recursos do meio. Em função do aumento da população idosa torna-se fundamental investigar as condições que interferem no bem-estar na senescência e os fatores associados à saúde dos idosos. O processo de diagnóstico psicodinâmico envolve uma situação bi-pessoal, com duração limitada de aproximadamente três encontros com o objetivo de descrição e compreensão da personalidade do participante, a mais completa e profunda possível. $\mathrm{O}$ objetivo do trabalho é o desenvolvimento de uma nova técnica de intervenção psicodinâmica, a caixa lúdica para idosos. Utilizando o modelo da caixa lúdica infantil, a técnica proposta possibilitou que cada um dos idosos depositasse em uma caixa vazia objetos de sua preferência, permitindo a expressão simbólica de conteúdos do mundo interno, circunstâncias de sua história pessoal e do grupo familiar e etário. Participaram da pesquisa oito idosos, distribuídos da seguinte forma: dois do Hospital Universitário da USP; dois da Universidade Aberta à Terceira Idade; dois de Instituição Asilar Particular; e dois da Clínica Psicológica "Durval Marcondes", do IPUSP. A pesquisa foi aprovada pelo Comitê de Ética em Pesquisa do Hospital Universitário da USP filiada ao SISNEP/Conep e aprovada pelo Comitê de Ética em Pesquisa com Seres Humanos do Instituto de Psicologia da USP. Foram utilizados a entrevista psicodiagnóstica semiestruturada; o mini-mental; a caixa lúdica para idosos; e a entrevista devolutiva. O procedimento da caixa lúdica para idosos permitiu a livre expressão de seu mundo interno através da manifestação de vivências, recordações, fantasias representadas pelos desejos inconscientes; medo, ansiedade e mecanismos de defesa. Além disso, o procedimento da caixa lúdica para idosos favorece a espontaneidade, a criatividade, a ousadia, a sensibilidade, o insight sobre novos sentidos para a história de vida, novas significações e a livre expressão de fantasias inconscientes, contribuindo assim para melhorar a compreensão psicodinâmica do idoso.

Palavras- chave: psicodiagnóstico, envelhecimento, psicodinâmica, psicologia do idoso, psicologia da saúde. 


\section{INTRODUÇÃO}

Acredito que seja interessante, neste momento, discorrer um pouco sobre o caminho percorrido até a elaboração do presente trabalho. Em minha experiência clínica o público idoso sempre despertou meu interesse, uma vez que o envelhecimento é um processo natural que ocorre desde o nascimento até a morte mostrando-se único para cada indivíduo. Em 2007, participei da elaboração e desenvolvimento de um projeto com idosos (LEONARDI; DAMASCENO; RODRIGUES, 2007) em uma instituição asilar particular. Este trabalho compreendia uma aproximação ao público idoso com o objetivo de compreender um pouco mais sobre sua qualidade de vida. Durante este processo, tivemos a supervisão e apoio do Laboratório Sujeito e Corpo (SUCOR) do Departamento de Psicologia Clínica do Instituto de Psicologia da USP, coordenado pelo prof. Dr. Avelino Luiz Rodrigues. O desenvolvimento deste projeto propiciou a criação de um instrumento inédito na área da psicologia: a Caixa Lúdica para Idosos.

A partir do material coletado através das entrevistas e escalas que avaliavam a qualidade de vida e a depressão naquele projeto, percebemos que os discursos dos idosos eram marcados por certo desconforto no tocante a serem muitas vezes envolvidos em atividades artísticas e manuais, não se identificando com as mesmas por se sentirem infantilizados.

Diante disso, refletimos sobre os instrumentos existentes na psicologia que pudessem permitir e/ou facilitar à aproximação ao público idoso conferindo-lhe a atenção e importância que merecem. Após uma deliberação sobre os instrumentos existentes na psicologia (avaliações sobre inteligência, memória retrospectiva, qualidade de vida, depressão, possível disfunção cognitiva, dinâmica e estrutura de personalidade, entre outros) sentimos a falta de um recurso que pudesse contemplar esta camada da população utilizando-se da projeção e ludicidade sem infantilizá-los e ao mesmo tempo diferenciando-se do formato conhecido de testes, escalas, desenhos, o ato de contar histórias, entre outros. Então, nos recordamos da técnica da caixa lúdica para crianças e percebemos que esta poderia ser aproveitada ao público idoso, com várias adaptações. Nasce a caixa lúdica para idosos (CLI). 
Com base na caixa lúdica idealizada por Melanie Klein, que consiste numa caixa com vários objetos e brinquedos com os quais a criança pode interagir, permitindo o acesso ao mundo interno, desenvolvemos a Caixa Lúdica para Idosos que tem o mesmo formato de uma caixa de sapatos, apresentada vazia e etiquetada com o nome do idoso. Trata-se de uma caixa com 29 centímetros de comprimento por 16 centímetros de largura, com tampa removível apresentada a cada idoso para efetuar sua construção.

Assim, cada idoso deve depositar objetos, fotografias, papéis e tudo que lhe for significativo, como lembranças, nome de pessoas, ou situações da vida, representações, que são escritas em um pedaço de papel e inseridas na caixa. Dessa forma o idoso pôde verbalizar e refletir sobre conteúdos de seu mundo interno, um espaço destinado à estes conteúdos os quais podem ser revistos quando de seu interesse.

Como consequência direta de sua repercussão positiva dentro do laboratório SUCOR, tal instrumento foi posteriormente parcialmente apresentado em congressos nacionais e internacionais, tendo sido contemplado com uma premiação no Congresso Sul Mineiro de Medicina Psicossomática (Prêmio Júlio de Melo Filho em 2007).

O panorama atual para o público idoso sugere ser bastante favorável ao desenvolvimento e aplicação deste instrumento, incrementando e favorecendo sua eclosão e importância na atualidade. Vamos aos dados. Existe uma grande preocupação quanto ao crescimento da população idosa no Brasil. Dados do censo 2000 apontam que $8,56 \%$ da população é representada por indivíduos acima de 60 anos, dos quais $55 \%$ são mulheres. Acredita-se que em 2020, haverá mais de 25 milhões de idosos, e infelizmente, os serviços de saúde pública não estão devidamente preparados para o atendimento dessa população crescente (IBGE, 2005). Pela lei 8842 de 4 de janeiro de 1994, presente na Política Nacional do Idoso, seção da finalidade, artigo segundo: "considera-se idoso, para efeito desta lei, a pessoa maior de sessenta anos de idade" (MINISTÉRIO DA SAÚDE, 2010). O idoso experimenta inúmeras dificuldades que vão desde questões como o suporte social inadequado até o dificultoso acesso a um atendimento de saúde de qualidade. O cuidado à saúde do idoso falha na promoção à saúde, no diagnóstico precoce, no tratamento, na prevenção de seqüelas e na reabilitação à vida em comunidade (PORCU; ALBRECHT; SILVA, 2002). 
Para se ter uma idéia da magnitude do problema, observe-se o exemplo da maior cidade do Brasil: São Paulo. Em 1996, a população era de 9.500 .000 e mais de 880.000 pessoas tinham 60 anos ou mais. Considerando que por volta de $30 \%$ da população idosa apresenta algum transtorno mental, esse município possuiria atualmente, aproximadamente, 240.000 idosos apresentando problemas psiquiátricos. Se for considerado o número de serviços disponíveis à saúde mental nesse município em torno de 100 serviços ambulatoriais e se compreender que o ideal é que esses pacientes sejam atendidos por equipes multiprofissionais com treinamento adequado para detecção e manejo desses transtornos de graus leve e moderado no indivíduo idoso, não há um bom prognóstico para esta situação (GARRIDO; MENEZES, 2002). As mudanças experimentadas pelo idoso, como a perda do cônjuge, a doença e a dependência física, a institucionalização, podem ser o ponto de partida para uma desestruturação psíquica.

A presente dissertação propõe o desenvolvimento de um procedimento clínico para facilitar o melhor manejo e compreensão do mundo interno dos idosos a partir do levantamento de suas percepções subjetivas propondo o aprimoramento de uma nova possibilidade de procedimento: a utilização da caixa lúdica em idosos (CLI). Destaca-se a relevância científica e social de se investigar as condições que interferem no bem-estar na senescência e os fatores associados à saúde no intuito de criar alternativas clínicas que configurem intervenções efetivas na área da saúde, buscando atender às demandas da população que envelhece (FLECK; CHACHAMOVICH; TRENTINI, 2003).

\section{CONCLUSÕES}

A caixa lúdica para idosos demonstrou ser um meio importante para a obtenção de informações acerca do paciente com vastidão e profundidade de conteúdos, ainda que tenha ocorrido num breve espaço de tempo (três entrevistas), conforme o conteúdo do capítulo da discussão e análise dos resultados,revelam. Todos os instrumentos utilizados nesta pesquisa estavam à serviço do pensamento clínico e somente possuem sentido dentro de um contexto e peculiaridade de cada indivíduo, não podendo ser consideradas 
à parte, como processos independentes ou fragmentados. A escolha dos instrumentos parece ter abarcado, como pretendia, os vários aspectos dos indivíduos buscando a sua compreensão da melhor forma possível. Dessa forma a pesquisadora entrou em contato com o conteúdo latente da personalidade dos sujeitos por meio de formas características de apreensão, chamadas de formas de pensamento clínico, ou seja, diferentes caminhos que o pensamento percorre na tentativa de diminuir a distância que existe entre os problemas e as respectivas respostas.

Com relação à complexidade e diversidade do ser humano, temos que a utilização de recursos lúdicos, como a caixa lúdica para idosos, pôde facilitar o processo de comunicação, favorecendo as pessoas que pudessem apresentar alguma dificuldade para expressar espontaneamente suas questões, pois favorecer a comunicação é também favorecer o surgimento de insights através da consciência dos fatos, além de possibilitar a diminuição de certas inibições, tendo a pesquisa englobado idosos de diferentes regiões, níveis de escolaridade, níveis sócio-econômicos-culturais, problemáticas, entre outros aspectos.

O uso da CLI -caixa lúdica para os idosos, possibilitou a aproximação, através de um procedimento clínico, à realidade psíquica desta população buscando identificar as necessidades do idoso enquanto ser humano, promovendo o desenvolvimento de um novo olhar cujo foco são os aspectos bio-psico-sociais. Pudemos perceber que as entrevistas realizadas com os participantes desta pesquisa revelaram que indivíduos se mostraram dispostos a participar, interessados, curiosos e criativos, estes foram estimulados a exercitar a capacidade reflexiva sobre a construção da caixa durante o processo. Os resultados obtidos nas entrevistas demonstraram ser este um momento importante na vida destes participantes na medida em que os mesmos sentiram-se escutados, recebendo atenção e sendo percebidos.

A utilização da caixa lúdica para idosos promove uma ampliação no conhecimento das possibilidades de ação com o público idoso, rompendo o formato social cristalizado que pode sugerir fragilidade, isolamento, decadência e poucas perspectivas. 
De acordo com os objetivos e desenvolvimento desta pesquisa, concluímos que o recurso lúdico forneceu um aparato motivacional, bem como funcionou como objeto intermediário que possibilitou a aproximação à realidade dos idosos, envolvendo liberdade de expressão, possibilitou a percepção, por parte da pesquisadora, das principais características de suas personalidades, favoreceu o resgate de experiências, sugerindo ser este um estudo que denota originalidade em sua proposta, ineditismo e singularidade buscando trazer contribuições ao público idoso bem como à sociedade como um todo.

\section{REFERÊNCIAS}

FLECK, M. P. A.; CHACHAMOVICH, E.; TRENTINI, C. M. Projeto Whooqol -old: métodos e resultados de grupos ficais no Brasil. Revista de Saúde Pública, São Paulo, v. 37, n. 6, p. 793-799, 2003.

GARRIDO R., MENEZES P. R. O Brasil está envelhecendo: boas e más notícias por uma perspectiva epidemiológica. Revista Brasileira de Psiquiatria, São Paulo, v. 24,n.1, p. 3-6, abr. 2002.

IBGE, Instituto Brasileiro de Geografia e Estatística. Disponível em: http://www.ibge.gov.br/home/. Acesso em: 22 ago. 2005.

LEONARDI, L. C.; DAMASCENO, D.; RODRIGUES, A. L. Desenvolvimento da Caixa Lúdica Old: uma nova técnica de intervenção junto aos idosos. In: CONGRESSO BRASILEIRO DE PSICOLOGIA DA SAÚDE, 9, 2007: São Bernardo do Campo, Universidade Metodista de São Paulo, Caderno de Resumos, São Bernardo do Campo, 2007, p. 42-43.

MIGLIAVACCA, E. M. A dimensão trágica do psiquismo: um ensaio. Revista Brasileira de Psicanálise, v. 38, n. 4, p. 843-866, 2004.

MINISTÉRIO DA SAÚDE, Brasília. Disponível em:

$<$ http://portal.saude.gov.br/portal/saude/default.cfm>. Acesso em: 20 de jan. 2010.

PORCU M, S. V. M.; ALBRECHT, N. R.; SILVA, S. P. V. Estudo comparativo sobre a prevalência de sintomas depressivos em idosos hospitalizados, institucionalizados e residentes na comunidade. Acta Scientiarum, Maringá, v. 24, n. 3, p. 713-717, 2002. 
